\title{
Diagnóstico ante una deformación sacular del ventrículo izquierdo en niños. No todo es lo que parece
}

\author{
Juan Manuel Carretero Bellon*,** \\ Alex Pérez Casares* \\ Laia Brunet García* \\ Fredy Hermogenes Prada* \\ Joan Sánchez de Toledo*
}

* Unidad de Cardiología Pediátrica. Hospital Sant Joan de Déu. Barcelona. España

** Unidad de Cardiología Pediátrica. Hospital Universitari Joan XXIII, Universitat Rovira i Virgili. Tarragona. España

Recibido: 04/04/2020

Aceptado: 08/10/2020

En línea: 31/12/2020

Citar como: Carretero Bellón JM, Pérez Casares A, Brunet García L, Prada FH, Sánchez de Toledo J. Diagnóstico ante una deformación sacular del ventrículo izquierdo en niños. No todo es lo que parece. Rev Ecocar Pract (RETIC). 2020 (Dic); 3 (3): 6-9. doi: 10.37615/retic.v3n3a14.

Cite this as: Carretero Bellón JM, Pérez Casares A, Brunet García L, Prada FH, Sánchez de Toledo J. Diagnosis of a saccular deformation of the left ventricle in children. Not everything is what it seems. Rev Ecocar Pract (RETIC). 2020 (Dic); 3 (3): 6-9. doi: 10.37615/retic.v3n3a14.

\begin{tabular}{l} 
Palabras clave \\
\hline Divertículo congénito \\
$\triangleright$ Defectos cardíacos \\
$\triangleright$ Cirugía
\end{tabular}

\begin{tabular}{l}
\hline Keywords \\
\hline$\triangleright$ Congenital ventricular \\
$\quad$ diverticulum \\
$\triangleright$ Heart defects \\
$\triangleright$ Surgery \\
\end{tabular}

\section{RESUMEN}

Presentamos dos casos clínicos de sendos niños con diagnóstico inicial de comunicación interventricular (CIV) con estenosis de tipo subpulmonar. La ecocardiografía inicial mostraba una posible CIV con algunas peculiaridades que precisaron más estudios de imagen. Estos estudios fueron la clave para el diagnóstico diferencial de una formación sacular en el septo basal por debajo de la válvula aórtica y que incluyó el divertículo o una cámara accesoria del ventrículo izquierdo. Ambos pacientes fueron intervenidos. Los hallazgos operatorios confirmaron el diagnóstico de divertículo de ventrículo izquierdo.

\section{Caso clínico 1}

Niña de 9 años derivada para evaluación de defecto septal perimembranoso. No había antecedentes personales ni familiares de interés. Estaba asintomática y en el examen físico sólo destacaba en la auscultación cardíaca un soplo III/VI holosistólico en foco paraesternal izquierdo.

La ecocardiografía transtorácica (ETT) mostró una estructura en forma de túnel que se originaba en el área del tabique ventricular membranoso por debajo de la válvula aórtica que se conectaba al ventrículo izquierdo (VI), dando la apariencia de una cámara accesoria. La comunicación interventricular (CIV) estaba muy cerca de la abertura del divertículo. No había gradiente Doppler a través del túnel, visualizando por color un flujo Doppler bidireccional de entrada y salida (Vídeo 1 y Vídeo 2).
Se realizó un cateterismo donde se objetivó la presencia de una formación sacular de $27 \times 16 \mathrm{~mm}$ en el septo membranoso debajo de la válvula aórtica, con un cuello de $10 \mathrm{~mm}$ de ancho que se comunicaba con la cavidad ventricular izquierda y con contracciones sincrónicas durante la sístole cardíaca (Vídeo 3 y Vídeo 4).

Había una comunicación restrictiva con un paso de contraste desde esta formación al tracto de salida del ventrículo derecho (TSVD).

La presión en esta formación era la misma que la del VI.

Aunque la paciente estaba asintomática, se realizó cirugía. A través de un abordaje transatrial, se cerró la comunicación entre el divertículo y el VD con puntos sueltos y posteriormente el divertículo con sutura en su orificio de entrada excluyéndolo del llenado ventricular. 


\section{Estudio por imagen}

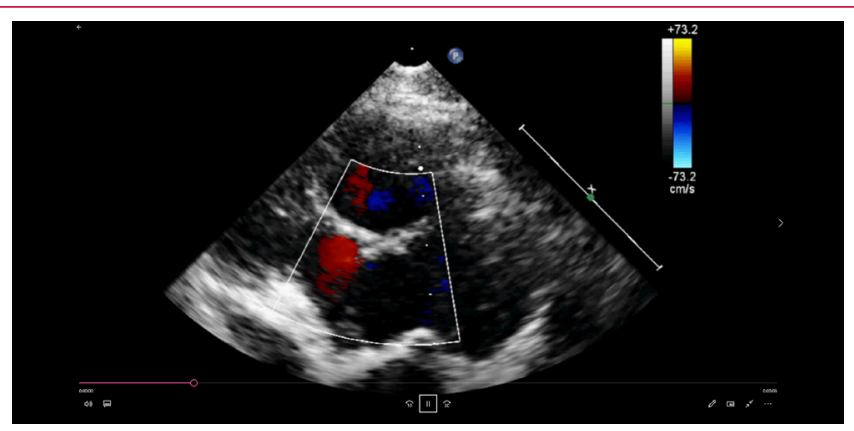

Vídeo 1. Ecocardiografía que muestra una estructura en forma de túnel conectada con el VI y con flujo bidireccional

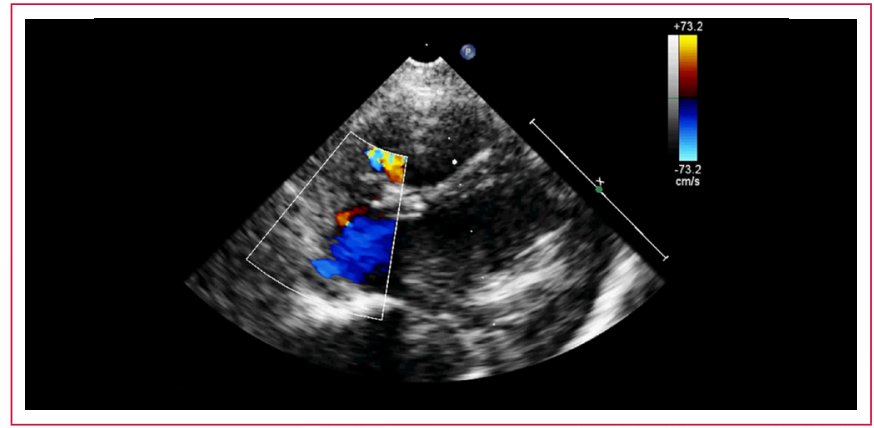

Vídeo 2. Detalle del Vídeo 1 en el que se observa, además, una comunicación de carácter restrictivo entre la estructura anómala y el VD

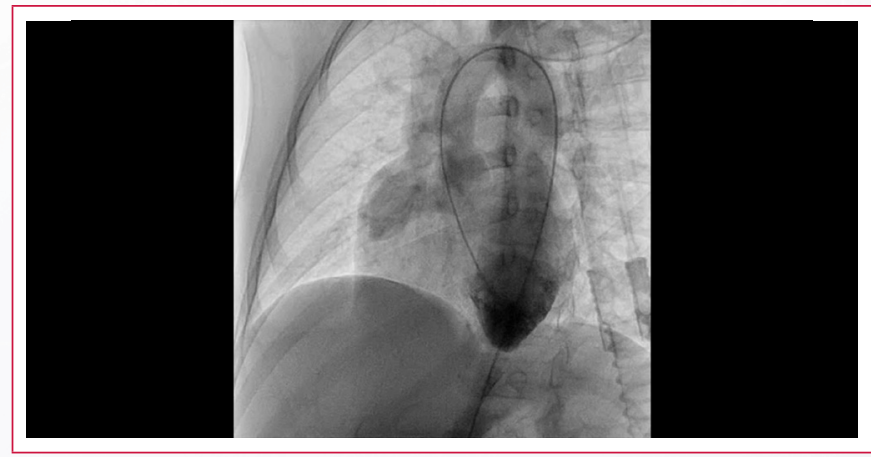

Vídeo 3. Ventriculografía izquierda en proyección lateral izquierda donde se observa el divertículo del VI conectado con el VI en el septo membranoso por debajo de la válvula aórtica y con contracción sincrónica

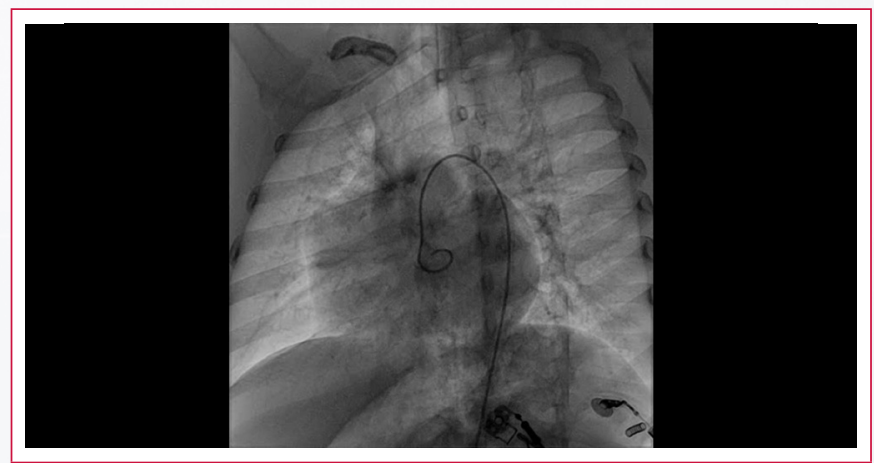

Vídeo 4. Ventriculografía izquierda en proyección lateral izquierda, con inyección en tracto de salida del VI en proyección lateral izquierda donde, además del divertículo, se aprecia una comunicación restrictiva con paso de contraste desde esta estructura al TSVD

\section{Caso clínico 2}

Niño de 3 años remitido para valorar cirugía por diagnóstico de CIV con estenosis subpulmonar. No había antecedentes personales ni familiares de interés. Estaba asintomático y en el examen físico destacaba sólo, a la auscultación cardíaca, un soplo III/VI holosistólico en el foco paraesternal izquierdo.

En la ETT se apreciaba una formación sacular de cuello ancho localizada debajo del plano valvular aórtico. Con Doppler color se observó un paso a través de este saco con un flujo bidireccional que nos alertó que no era sugestivo de CIV. La ecocardiografía transesofágica (ETE) (Figura 1) y el cateterismo cardíaco confirmaron los datos. El cateterismo mostró que la lesión tenía las mismas características que las del primer caso, con una boca de $7 \mathrm{~mm}$ y una longitud de 30 mm y con una conexión restrictiva al TSVD (Vídeo 5). La presión en el divertículo era la misma que en el VI.

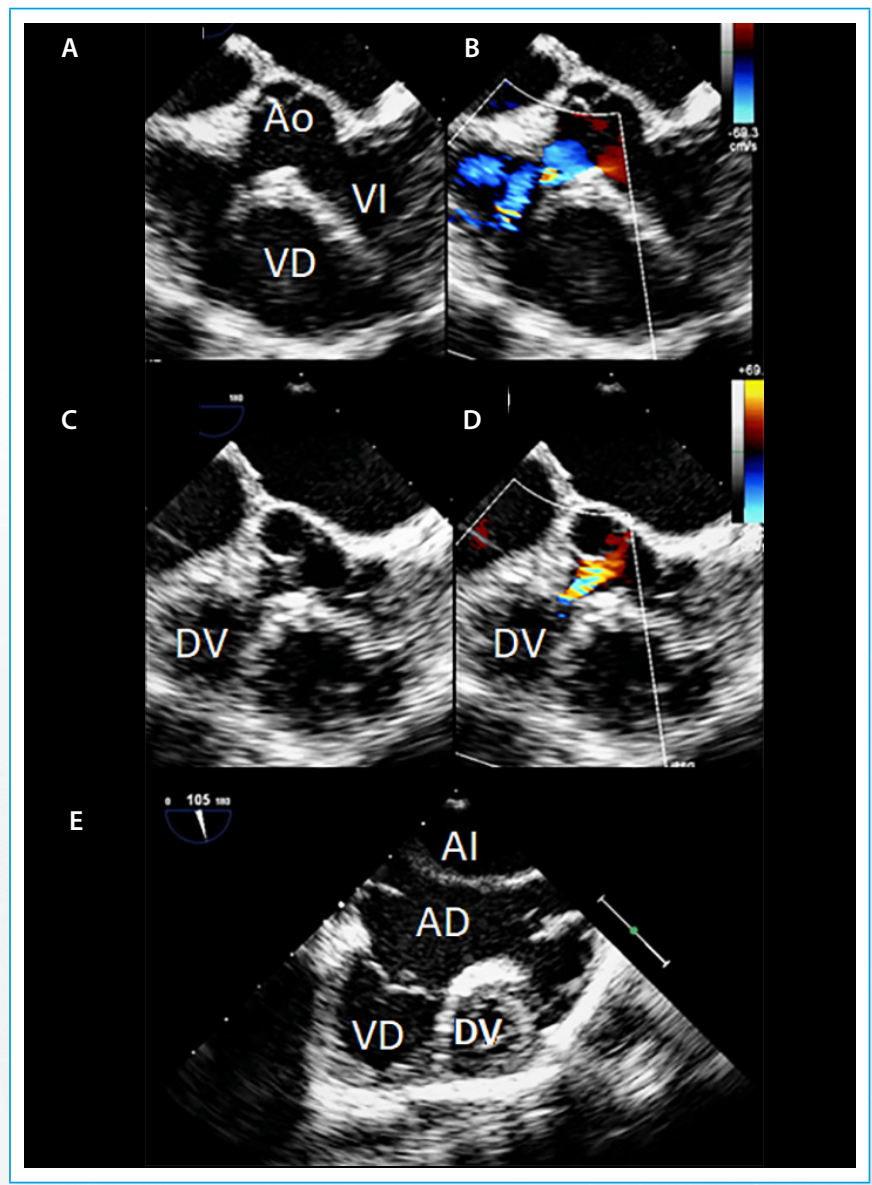

Figura 1. Ecocardiografia transesofagica. A-D. Corte de 4 cámaras que muestra esta estructura en forma de túnel con parte de la pared, que conecta con Vl y con flujo bidireccional. En D. se observa corte transversal a $105^{\circ}$ donde se observa el divertículo con su capa muscular. VI: ventrículo izquierdo. VD: ventrículo derecho. DVI: divertículo. Ao: aorta. Al: aurícula izquierda. AD: aurícula derecha

En este segundo niño se solicitó también una resonancia magnética (RM) donde se observó un divertículo de $30 \mathrm{~mm}$ de longitud y $20 \mathrm{~mm}$ de ancho de forma sacular con un cuello de $7 \mathrm{~mm}$ en región subaórtica que se extendía hacia cara anterior por encima del VD, con capa muscular y contracción sincrónica con el resto del miocardio. En la angio-RM se observó que el divertículo se llenaba en la misma fase del VI con el que estaba comunicado (Figura 2). La reconstrucción 3D aclaró más la relación del divertículo con las estructuras circundantes (Vídeo 6). Se realizó una corrección quirúrgica con el mismo tipo de cirugía que en el primer caso. 


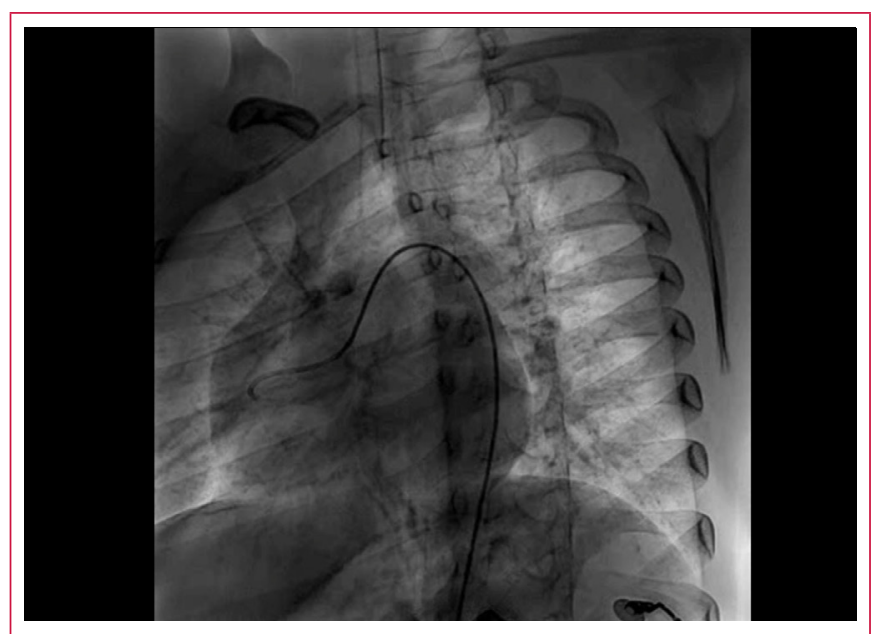

Vídeo 5. Angiografía selectiva en proyección lateral izquierda a nivel del divertículo que exhibe una contracción sincrónica con el Vl y con una comunicación restrictiva con el tracto de salida del ventrículo derecho

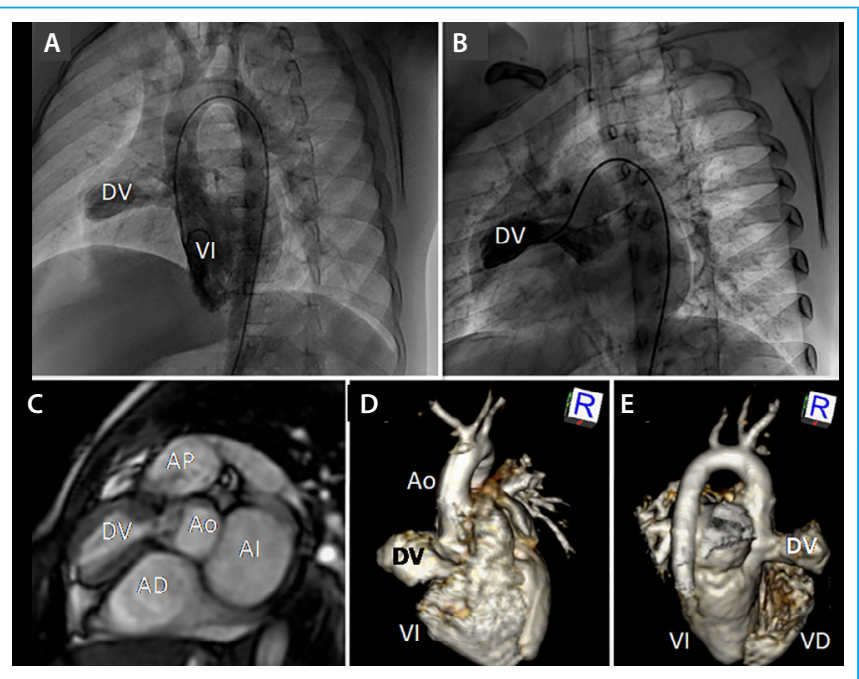

Figura 2. Imágenes combinadas de la angiografía y RM para mostrar la correlación entre ambos estudios. A: angiografía ventricular izquierda que muestra el divertículo. B: angiografía selectiva en el divertículo. C: RM en eje corto donde se muestra el divertículo con la presencia de capa muscular. D y E: visión tridimensional del divertículo en su cara anterior y cara posterior (AD: aurícula derecha; Al: aurícula izquierda; Ao: aorta; AP: arteria pulmonar; DV: divertículo; VD: ventrículo derecho; VI: ventrículo izquierdo)

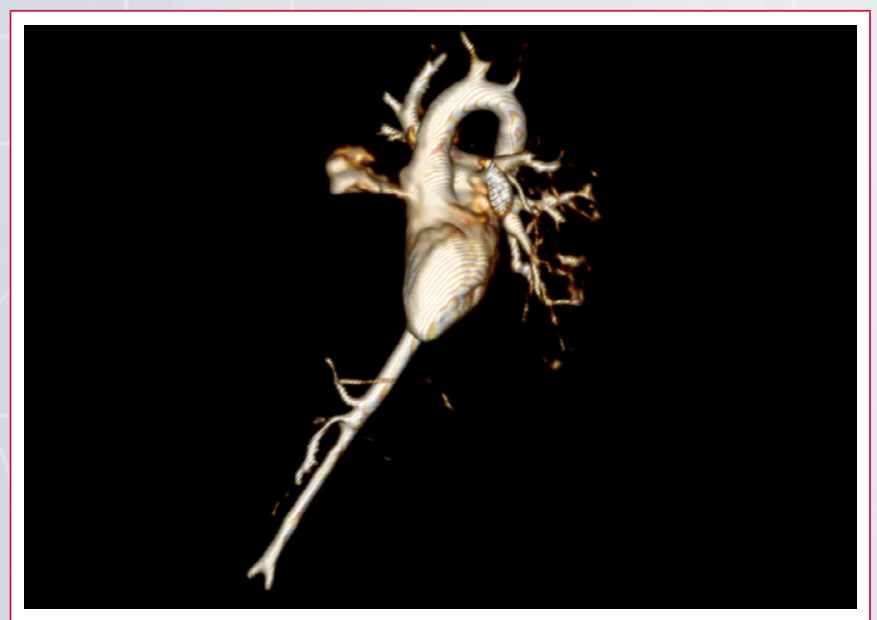

Vídeo 6. Reconstrucción tridimensional en RM

\section{Discusión}

El diagnóstico diferencial de las formaciones congénitas saculares en el VI, conocidas en inglés como "outpouchings" congénitos del VI incluyen divertículos ventriculares congénitos (DVI), aneurismas ventriculares congénitos $(A V I)$, VI de doble cámara, VI accesorio, hendiduras y criptas. No se ha establecido una clasificación única, y estos términos se usan indistintamente, con terminología confusa $a^{(1,2)}$

La etiología es muchas veces desconocida. En el caso de DVI y AVI aislados no apicales, se ha atribuido a un defecto focal de la pared ventricular muscular debido a una anomalía intrínseca en la embriogénesis ${ }^{(3)}$. Estas formaciones saculares pueden ser adquiridas durante el periodo fetal o neonatal, debido a una infección viral, anomalías coronarias o vasculitis, lo que puede provocar una debilidad localizada de la pared del VI con protrusión gradual, debido a la alta presión intraventricular ${ }^{(1)}$

El DVI es una malformación congénita rara y es habitualmente un hallazgo incidental, generalmente asociado a otras malformaciones congénitas, cardíacas o no cardíacas, destacando las malformaciones toracoabdominales, asociación ya conocida desde la descripción de la pentalogía de Cantrel|(4). En un 30\% de los casos son aislados. Se encuentran con mayor frecuencia en el VI, pero todas las cámaras pueden verse afectadas. El DVI tiene como características anatómicas un cuello estrecho que se comunica con la cavidad ventricular e histológicamente está constituido por una pared ventricular normal y/o predominantemente tejido conectivo. Por tanto, los divertículos podrían clasificarse en tipo muscular y tipo fibroso dependiendo de la cantidad de fibras de miocardio involucradas ${ }^{(5)}$. Los musculares contienen todas las capas del miocardio ventricular y muestran una función contráctil sincrónica con el ventrículo. Los fibrosos tienen tejido conectivo compuesto de reticulina y las fibras musculares son escasas o ausentes, tienen una contracción acinética o discinética y generalmente un cuello más ancho. Para algunos autores, el tipo fibroso es un seudodivertículo y no uno verdadero, lo que agrega un elemento adicional de confusión terminológica ${ }^{(1,2)}$. Otros autores los clasifican, en función de su localización, en apicales y no apicales ${ }^{(6)}$.

Los AVI tienen una base amplia y en términos histológicos carecen de capa de músculo miocárdico, tienen una sola capa de tejido fibroelástico y exhiben una expansión paradójica durante la sístole $e^{(1,3)}$

El diagnóstico inicial de sospecha se basa en la ecocardiografía, pero requiere otras técnicas de imagen para ser correcto, aunque el diagnóstico de confirmación es histológico. Entre las pruebas de imagen, la RM ha adquirido un papel primordial(1), siendo una técnica no invasiva, no ionizante y que confirma la presencia, tamaño, extensión y la caracterización tisular precisa de estas formaciones saculares. Las secuencias de sangre negra y las secuencias de precesión libre en estado estacionario (SSFP) permiten una caracterización precisa del tejido. Además, la detección de realce tardío con secuencias potenciadas en T1 permite el diagnóstico de tejido fibroso o necrótico, y es muy útil en el diagnóstico diferencial entre divertículos y aneurismas.

Se han reportado pocos casos en la edad pediátrica. En un artículo, se describen cinco pacientes con presencia de un divertículo anterosuperior del VD, asociados cuatro de ellos a CIV y otro sin ella, siendo este último caso muy similar a los pacientes descritos en este trabajo(7).

El tratamiento en pacientes sintomáticos es quirúrgico, pero no existen recomendaciones claras en cuanto al tratamiento en los asintomáticos. Algunos proponen la exclusión o resección para prevenir potenciales complicaciones como endocarditis, formación de trombos, arritmias y ruptura, mientras que otros proponen una conducta conservadora debido al bajo riesgo de com- 
plicaciones que se han observado en el seguimiento a largo plazo. En nuestro caso, optamos por la primera opción, debido al tamaño de estas formaciones y en prevención de las complicaciones reportadas en la literatura ${ }^{(8)}$.

\section{Conclusión}

Los divertículos congénitos del VI son un tipo de malformación cardíaca infrecuente consistente en el desarrollo de una cavidad accesoria con pared muscular que se comunica con un cuello estrecho con la cavidad principal y tienen actividad contráctil sincrónica con el ventrículo. Su diagnóstico se sospecha con el ecocardiograma, pero muchas veces requieren estudio adicional con otras técnicas de imagen para hacer el diagnóstico diferencial de "outpouching" del VI.

\section{Ideas para recordar}

- Ante una CIV subaórtica con flujo de entrada y salida debemos realizar el diagnóstico diferencial con los "outpouchings" o formaciones saculares del VI. La contracción sistólica sincrónica con el ventrículo es un hallazgo que nos puede orientar en el diagnóstico de divertículo.

- La RM cardíaca es la técnica de referencia en el diagnostico diferencial de estas formaciones saculares ventriculares congénitas, incluidos DVI, AVI y VI accesorio, debido a su alta resolución espacial y a que permiten tanto una evaluación funcional de su pared como una caracterización precisa del tejido.

\section{Bibliografía}

1. Cresti A, Cannarile P, Aldi E, Solari M, Sposato B, Franci L, Limbruno U. Multimodality imaging and clinical significance of congenital ventricular outpouchings: recesses, diverticula, aneurysms, clefts, and crypts. J Cardiovasc Echogr 2018 Jan-Mar; 28 (1): 9-17.

2. Malakan Rad E, Awad S, Hijazi ZM. Congenital left ventricular outpouchings: a systematic review of 839 cases and introduction of a novel classification after two centuries. Congenit Heart Dis 2014 Nov-Dec; 9 (6): 498-511.

3. Marijon E, Ou P, Fermont L, Concordet S, Le Bidois J, Sidi D, et al. Diagnosis and outcome in congenital ventricular diverticulum and aneurysm. J Thorac Cardiovasc Surg 2006; 131: 433-437.

4. Cantrell JR, Haller JA, Ravitch MM. A syndrome of congenital defects involving the abdominal wall, sternum, diaphragm, pericardium, and heart. Surg Gynecol Obstet 1958; 107: 602-614.

5. Ferreira AM, Café H, Santos KR, Toste J, Marques H. Congenital muscular diverticulum of the left ventricular apex. Int J Cardiovasc Imaging 2014; 30 (4): 783-784.

6. Nam KH, Kwon JY, Son GH, Cho NH, Park YW, Kim YH, et al. Prenatally diagnosed left ventricular diverticulum with thoracoabdominal wall defect. A case and review of the literature. J Perinatol 2010; 30: 760-762.

7. Wiegand G, Rauch R, Singer H, Koch A, Hofbeck M. Anterosuperior diverticula of the right ventricle: morphological spectrum and long-term outcome of a distinct cardiac anomaly. Pediatric Cardiology 2014 Feb; 35 (6): 983-989.

8. Partington SL, Ali B, Daly RP, Koplan BA, Lilly LS, Solomon SD, Kwong RY, Blankstein R. Initial presentation of an accessory left ventricle in a patient with syncope. Circulation 2010 May 18; 121 (19): e401-e403. 